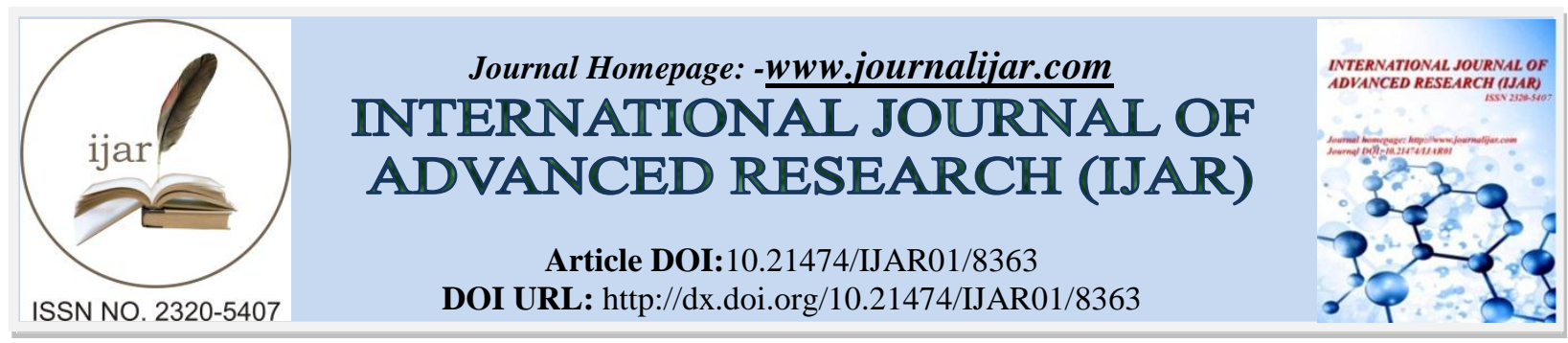

RESEARCH ARTICLE

\title{
CMR PROFILE OF ARRYTHMOGENIC RIGHT VENTRICULARDYSPLASIA INMOROCCO: DESCRIPTIVE CLINICALSTUDY OF 31 PATIENTS.
}

Doghmi Nawal, Sanoussi Hamza, Fellat Ibtissam and Cherti Mohammed. Cardiology Department "B”, IBN SINA hospital, Rabat, Morocco.

\section{Manuscript Info}

\section{Manuscript History}

Received: 08 November 2018

Final Accepted: 10 December 2018

Published: January 2019

Key words:-

ARVD/C; CMR; Fat.

\begin{abstract}
Objectives: The aim of our study is to expose our center experience in ARVD/C diagnosis based on CMR.

Methods: A retrospectivestudy, carried out over a period of two years (February 2012 to March 2014) of 31 patients with suspected ARVD/C based on CMR findings using revised Task Force Criteria (TFC).

Results: The mean age was $44,9+/-13,6$ years with extremes ranging from 18 to 64 years. The male to female ratio was 2,9. All patients presented with arrhythmias with a majority of ventricular extrasystoles (48\%) and ventricular tachycardia (39\%). 11 patients (35\%) were classified as confirmed ARVD/C. All patients with confirmed ARVD/C had RV dilatation. The mean RVEDV was $173 \mathrm{ml} \mathrm{+/-} 70$. The mean ejection fraction (EF) of RV was $54 \%+/-9,8.90 \%$ of patients had RV dyskinesia mostly located in the lateral wall (60\%). Delayed myocardial enhancement appeared in $86 \%$ of cases. Fatty infiltration of the myocardium was observed in $14 \%$ of cases and was almost located in the lateral wall.

Conclusion: This study shows the CMR profile of ARVD/C in Moroccan patients. Our results are based on a small number of $\mathrm{ARVD} / \mathrm{C}$ patients, and further studies with more patients and prospective design are warranted.
\end{abstract}

Copy Right, IJAR, 2018, All rights reserved.

\section{Introduction:-}

Arrythmogenic right ventricular dysplasia/ Cardiomyopathy (ARVD/C) results from fibro-fatty replacement of the right ventricular wall, a condition that leads to arrythmogenicity, progressive right ventricular failure, and sudden death [1,2]. The diagnosis of ARVD/ $\mathrm{C}$ is based on structural, histological, electrocardiographic, arrythmic and genetic factors proposed by ARVD/ C Task force in 1994 [3]. Modified Task Force Criteria (TFC) was proposed in 2010 by Marcus FI et al [4]. Cardiovascular Magnetic Resonance (CMR) is nowadays commonly used in the diagnosis of $\mathrm{ARVD} / \mathrm{C}$.

The aim of ourstudyis to expose our center experience in ARVD/C diagnosisbased on CMR.

Corresponding Author: Sanoussi Hamza.

Address:-Cardiology Department “B”, IBN SINA hospital, Rabat, Morocco. 


\section{Material and Methods:}

Type of study:

A retrospective study, carried out over a period of two years (February 2012 to March 2014) of 31 patients with suspected ARVD/C based on echocardiography and CMR findings using revised TFC:

\section{Major criteria:}

Regional RV akinesia or dyskinesia or dyssynchronous RV contraction and 1 of the following:

1. Ratio of RV end-diastolic volume to BSA $\geq 110 \mathrm{~mL} / \mathrm{m}^{2}$ (male) or $\geq 100 \mathrm{~mL} / \mathrm{m}^{2}$ (female)

2. or RV ejection fraction $\leq 40 \%$

\section{Minor criteria:}

Regional RV akinesia or dyskinesia or dyssynchronous RV contraction and 1 of the following:

Ratio of RV end-diastolic volume to BSA $\geq 100$ to $<110 \mathrm{~mL} / \mathrm{m}^{2}$ (male) or $\geq 90$ to $<100 \mathrm{~mL} / \mathrm{m}^{2}$ (female) or RV ejection fraction $>40 \%$ to $\leq 45 \%$

\section{CMR protocol:}

CMR was performed using a 1.5 Tesla magnetic resonance scanner (Siemens Medical Systems). An eight-element cardiac phased-array receiver surface coil, with breath- holding in expiration and electrocardiogram (ECG) gating, wasused for signal reception. Images wereobtained in two chamber, four-chamber, and short-axis (from the atrioventricular ring to the apex) planes.

RV function analysis was done using Argus analysis software (Siemens Medical Solutions). The quantitative analysis of RV volumes and function were collected. The endocardial RV contours weredrawn for each diastolic and systolic frame.

Severity of wall motion abnormalities was rated depending on the detection of hypokinetic, akinetic, dyskinetic or aneurysmal segments.

\section{Results:}

\section{Clinical characteristics:}

The mean age was $44,9+/-13,6$ years with extremes ranging from 18 to 64 years. The male to female ratio was 2,9. Cardiovascular risk factors were presented as follows: $12 \%$ of patients had arterial hypertension, $16 \%$ had a known diagnosis of diabetes and $12 \%$ had dyslipidemia. Nearly $12 \%$ of patients had a family history of ARVD/C. All patients presented with arrhythmias (Figure 1), with a higher frequencyof ventricular extrasystoles (48\%) and ventricular tachycardia (39\%).

Usingmodified TFC, 11 patients (35\%) were classified as confirmed ARVD/C.

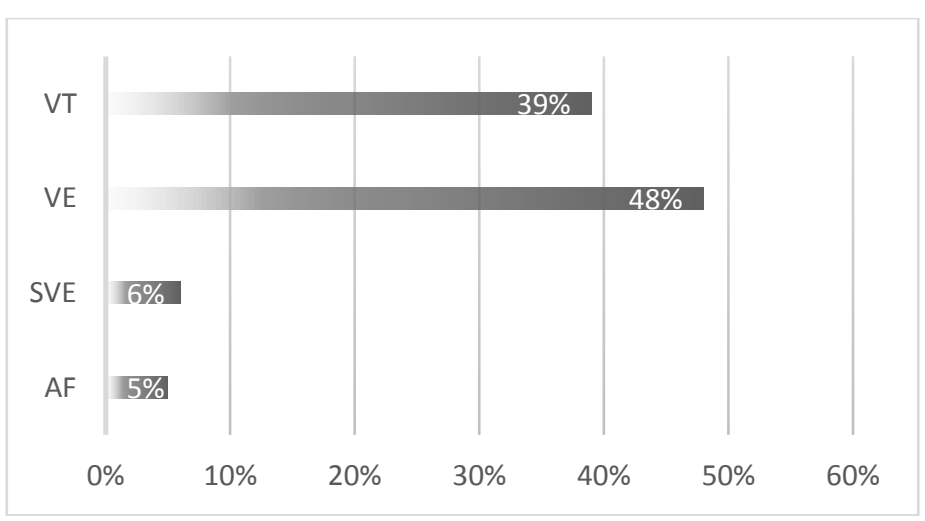

Figure1: Cardiac Arrhythmias in suspected ARVD 


\section{CMR findings:}

CMR features suggestive of ARVD/C wereseen in 11 patients. All patients withconfirmed ARVD/C had RV dilatation. The RV volumetric data are presented in (Table Ia, Table Ib).

The meanvalues of RV ejection fraction (EF) and LVEF were 54\%+/-9,8, and 62\% +/- 5,4 respectively.

Table I a: Mean RVEDV in confirmed and non confirmed ARVD/C

\begin{tabular}{|lll|}
\hline & Mean RVEDV & Normal values \\
\hline Confirmed ARVD/C (11) & $173 \mathrm{ml}+/-70$ & $56-269 \mathrm{ml}$ \\
\hline No confirmed ARVD/C (20) & $98,9 \mathrm{ml}+/-23$ & $30-154 \mathrm{ml}$ \\
\hline
\end{tabular}

Table I b: Mean RVEDV and RVEDVI in men and women with confirmed and non confirmed ARVD/C

\begin{tabular}{|l|l|cc|}
\hline Characteristics & Number & RVEDV & RVEDVI \\
\hline Confirmed ARVD/C (11) & Men (10) & $166,11 \mathrm{ml}$ & $87,4 \mathrm{ml} / \mathrm{m} 2$ \\
& Women (1) & $235 \mathrm{ml}$ & $146 \mathrm{ml} / \mathrm{m} 2$ \\
\hline No confirmed ARVD/C (20) & Men & $105,7 \mathrm{ml}$ & $55 \mathrm{ml} / \mathrm{m} 2$ \\
& Women & $86,2 \mathrm{ml}$ & $53 \mathrm{ml} / \mathrm{m} 2$ \\
\hline
\end{tabular}

RVED: Right ventricular end diastolic volume; RVEDVI: Right ventricular end diastolic volume index.

$90 \%$ of patients had RV dyskinesia located in the lateral wall in $60 \%$ of cases, in the anterior wall in $30 \%$ of cases and $10 \%$ in RV apex. A case of RV aneurysm was reported (Figure 2).

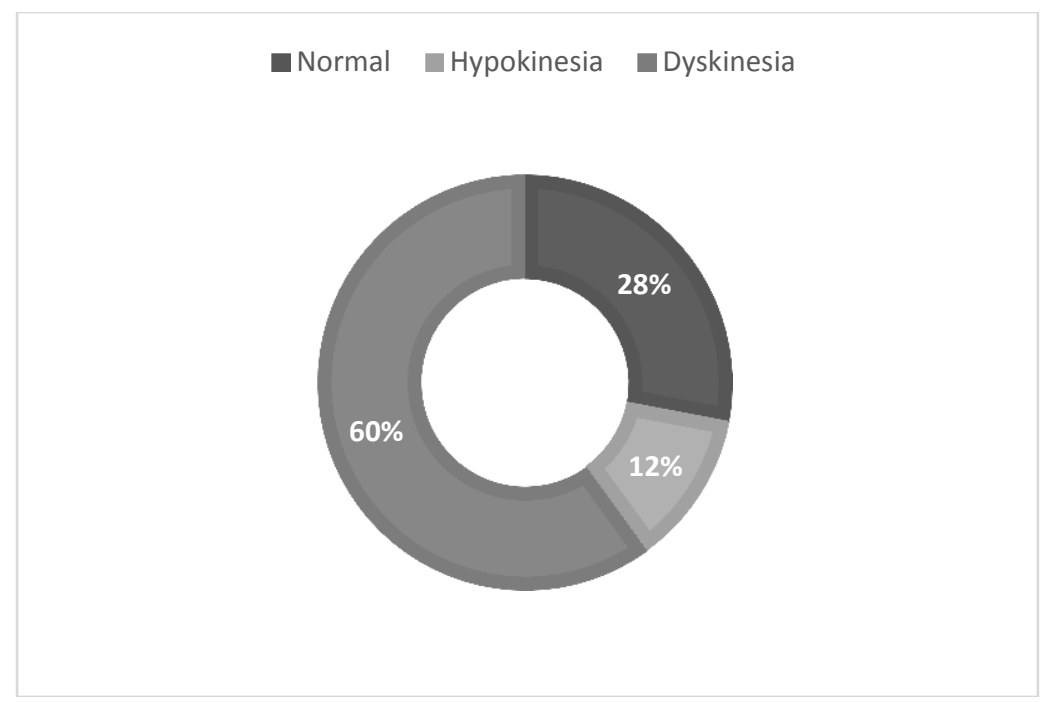

Figure 2: RV wall motion abnormalities

Delayed myocardial enhancement appeared in $86 \%$ of cases. The distrubition was varied and included lateral wall (55\%), basal wall (33\%) and RV apex. Fatty infiltration of the myocardium appeared in $14 \%$ of cases and was mostly located in the lateralwall. (Figure 3) 


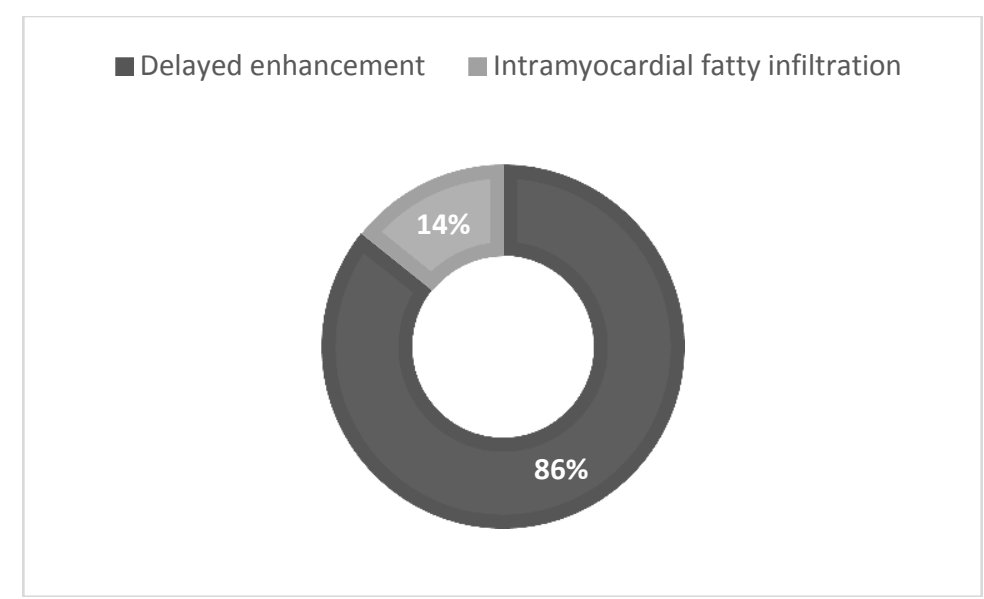

Figure 3: Late gadolinium enhancement in CMR findings.

\section{Discussion:-}

Arrhythmogenic right ventricular dysplasia is characterised by fatty or fibrofatty infiltration of RVmyocardium, which leads to electrical instability. The diagnosis is based on anatomopathology findings. Others diagnostic tools are still controversy [5].

CMR has emerged as an important imaging modality in the diagnosis and evaluation of patients of ARVD/C. It remains the best method to assess the volume of cardiac cavities and allows a good visualization of the RV in three dimensional multiplanar capabilities [6,7].

In 1994, the Task Force of the European society of cardiology and the scientific council on cardiomyopathies of the international society and Federation of cardiology proposed a set of criteria. These original task force criteria were considered highly specific but may have a lack of sensitivity. In 2010, TFC has been revised to add size quantification and RV function assessment [8].

In our study, we performed CMR to increase the specificity rate in patients with suspected ARVD/C.

CMR abnormalities in ARVD/C can be divided into two groups:

Functional abnormalities: RV dilatation, RV diastolic/systolic dysfunction, regional wall motion abnormalities and focal aneurysms.

Morphological abnormalities: Focal wall thickening, trabecular hypertrophy, wall hypertrophy, disarray moderator band hypertrophy, right ventricular outflow tract and intramyocardial fatty infiltration.

In our study, we found that all patients with confirmed ARVD/C had RV dilatation. $90 \%$ of patients had RV dyskinesia mostlyl ocated in the lateral wall.

Fatty infiltration of the myocardium appeared in $14 \%$ of cases. This was confirmed by Bomma et al. [9], which reported that fat signal can be misleading in ARVC diagnosis.

\section{Conclusion:-}

This study shows the CMR profile of ARVD/C in Moroccan patients. Our results are based on small number of ARVD/C patients, and further studies with more patients and prospective design are warranted.

\section{References:-}

1. Fontaine G, Guiraudon, et al. Stimulation studies and epicardialmapping in ventricular tachycardia : Study of mechanism and selection for surgery. In: Kulbertus H, ed. Reentrant arrhythmias, mechanism and treatment. Lancaster : MTP Publishing, 1977 : 334-350

2. Franck R, Fontaine G, et al. ectrocardiologie de 4 cas de dysplasie ventriculaire droite arythmogène. Arch Mal Cœur $1978 ; 71: 963-72$ 
3. McKenna WJ, Thiene G, et al. Diagnosis of arrythmogenic right ventricular dysplasia/cardiomyopathy: Task force of the working group of Myocardial and pericardial disease of the European Society of Cardiology and of the Scientific Council on Cardiomyopathies of the International Society and federation of Cardiology. Br Heart J $1994 ; 71(3): 215-8$

4. Marcus FI, McKenna WJ, et al. Diagnosis of arrythmogenic right ventricular cardiomyopathy/dysplasia; proposed modification of the task force criteria. Circulation $2010 ; 121: 1533-416-21$

5. Pennel, D.J. Clinical indications for cardiovascular magnetic resonance (CMRI): Consensus panel report.Eur. Heart J. 2004, 25, 1940-1965.

6. Casolo, G.C.; Poggesi, L.; Boddi, M.; Fazi, A.; Bartolozzi, C.; Lizzadro, G.; Dabizzi, R.P. ECG-gated magnetic resonance imaging in right ventricular dysplasia. Am. Heart J. 1987, 113, 1245-1248.

7. Pennell D, Casolo G: Right ventricle arrhythmia: emergence of magneticresonanceimaging as an investigating tool. EurHeart J 1997, 18(12): 1843-1845.

8. Emmanuelle $\mathrm{V}$ et al. :Impact of the Revision of Arrhythmogenic Right VentricularCardiomyopathy/DysplasiaTask Force Criteria on ItsPrevalence by CMR Criteria: JACC: Cardiovascular imaging https://doi.org/10.1016/j.jcmg.2011.01.005

9. Molinari, G.; Sardanelli, F.; Gaita, F.; Ottonello, C.; Richiardi, E.; Parodi, R.C.; Masperone, M.A.; Caponnetto, S. Right ventricular dysplasia as a generalized cardiomyopathy? Findings on magneticresonanceimaging. Eur. Heart J. 1995, 16, 1619-1624. 